\title{
A comprehensive assessment of urban vulnerability and its spatial differentiation in China
}

\author{
FANG Chuanglin ${ }^{1}$, 'WANG Yan ${ }^{1}$, FANG Jiawen² \\ 1. Institute of Geographic Sciences and Natural Resources Research, CAS, Beijing 100101, China; \\ 2. College of Urban and Environmental Sciences, Peking University, Beijing 100871, China
}

\begin{abstract}
The urban vulnerability poses a serious challenge to achieving sustainable development. With the concentration of the population and the economy, cities must manage the higher frequencies and risks of various hazards and are becoming more vulnerable. Research on the assessment and regulatory control of urban vulnerability is of great significance for both urbanization quality improvement and sustainable development in China or other countries in the world. Because of the complexity of cities and vulnerability concepts, existing studies have focused on different aspects of urban vulnerability. And the research content of urban vulnerability is scattered and relatively independent, leading to a lack of comparability among the research data and resulting in tremendous difficulties in summarizing the conclusions through comparison of independent research data. Therefore the goal of this study was to construct urban vulnerability index (UVI) from the perspective of sustainable development that could assess urban vulnerability comprehensively. In this study, we selected 10 subindexes involving 36 specific parameters from four aspects (resources, eco-environmental systems, economics, and social development) to construct a comprehensive index system. We also established the standard values of measurements. Then we take 288 prefecture-level cities in China as a study area and evaluate its overall urban vulnerability and its spatial differentiation. Results indicate that urban vulnerability of China has a remarkable spatial differentiation of both "gradient distribution" and "clustered distribution"; the extent of urban vulnerability corresponds to city size, the bigger the city, the lower its vulnerability; resource-based cities are more vulnerable than comprehensive cities; a city's economic growth rate does not reflect the extent of its urban vulnerability. Further, we offer a few suggestions to cope with urban vulnerability in China.
\end{abstract}

Keywords: urban vulnerability; comprehensive assessment; spatial differentiation; sustainable development; China

Received: 2015-07-16 Accepted: 2015-08-20

Foundation: National Natural Science Foundation of China, No.41371177

Author: Fang Chuanglin (1966-), Professor, specialized in land use and resources \& urban geography.

E-mail: fangcl@igsnrr.ac.cn

*Corresponding author: Wang Yan (1984-), $\mathrm{PhD}$, specialized in economic geography, and urban \& regional planning.

E-mail: wangzy816@163.com 


\section{Introduction}

\subsection{Background}

China is in a rapid urbanization stage: in the next 20 years, more than $60 \%$ of the population will live in the nation's cities (Fang, 2009). With the concentration of the population and the economy, cities must manage the higher frequencies and risks of various hazards and are becoming more vulnerable. In addition, new-type urbanization requires the reduction of urban vulnerability and the improvement of urbanization quality. Therefore, research on urban vulnerability is an important scientific tool to explore the harmonious coexistence of the human-environmental systems, and urban vulnerability has become a key topic that needs to be strengthened in the forefront of research.

The concept of "vulnerability" originated from studies on natural disasters (Janssena et al., 2006). In the 1970s, White (1974) and Burton (1978) introduced this concept in their studies of natural disasters. Later, in the 1980s, this concept was expanded to research on starvation and food security, poverty, and development. For example, Sen (1981) adopted this concept in research on starvation and food security, and Chambers (1989) and Swift (1989) introduced it into the research field of poverty and development. In the 1990s, researchers concentrating on natural disasters began to pay attention to the effect of human activities on global environmental change, in particular, their effect on vulnerability to climate change. Liverman (1990) used the concept of "vulnerability" in research on global environmental change. During this period, a rapidly increasing number of studies in the field of human dimensions of global environmental change focused on vulnerability (Janssena et al., 2006; Janssen, 2007). In addition, research on vulnerability to climate change plays a pivotal role in the development of vulnerability research. Scholars have persistently tracked the studies of the Intergovernmental Panel on Climate Change (IPCC) on vulnerability to climate change and have analyzed the concept of vulnerability proposed by the IPCC (Watson et al., 1996; Watson et al., 1998; McCarthy et al., 2001). Moreover, research on poverty was also advanced during this period, which not only considered poverty caused by low income according to the traditional definition but also extended the research scope to the "poverty" of developmental capacity (Roberts and Yang, 2003). Referencing a power-losing theory emerging in food security research, developmental economic scholars conducted studies on vulnerability associated with sustainable livelihoods and poverty (Adger, 2006). In the 21st century, the vulnerability of coupled systems, particularly the coupled human-environment system and the coupled socio-ecological system, began to attract attention, leading to numerous studies on vulnerability on a specific spatial scale of coupled systems. In general, evolution of the "vulnerability" concept resulted from the processes of content extension and multidisciplinary comprehensive integration (Kelly and Adger, 2000). In particular, "vulnerability" in research on the human-environment system has become a collective concept (Newell et al., 2005), which includes the components of risk, fragility, marginalization, natural disaster, sensitivity, adaption and response, adaptive potential, resilience, etc. (Birkmann, 2007; Liverman, 2000). Humane studies have extended this concept to "vulnerability" in the pure sense of economic social systems (Adger et al., 2004; Adrianto and Matsuda, 2002). Related studies have emphasized the identification of vulnerable populations or groups and vulnerable regions and have focused on intraregional or interregional compara- 
tive analyses of vulnerability under the same disturbance background. These studies have generally been more focused on the economic, political, management system, and cultural factors that easily affect either human societies or groups, along with the sociocultural mechanisms and countermeasures that can be used to restore the resilience of both natural environmental systems and economic social systems (Li and Zhang, 2011).

\subsection{Analysis of existing studies}

Until now, domestic and international scholars have conducted both multidimensional and multilevel studies on urban vulnerability in different fields. In addition to a traditional risk-hazard research viewpoint, urban vulnerability research has achieved much in various fields, including sustainability science, socioecological resilience research, adaptability science, and complex human-environmental systems. The vulnerability studies in different fields are associated and have overlapped with each other, forming the core of vulnerability research. Urban vulnerability research has covered a broad range of topics, including social vulnerability to environmental hazards (Siagian et al., 2014; Cutter et al., 2003; Cutter, 1996), urban vulnerability to terrorist attacks (Walter et al., 2007), urban vulnerability to climate change (Grasso et al., 2014; Renaud and Perez, 2010; Hay and Mimura, 2006), urban internal vulnerability to heat (Joyce et al., 2014), urban vulnerability to natural disasters (Zhou et al., 2014; Usha, 2012), etc. Urban vulnerability research has involved cities in both developed and developing countries, such as the United States (Cutter et al., 2003), Australia (Abbas and Fahim, 2015), Chile (Muller et al., 2011), Kenya (Oluoko, 2011), South Korea (Koh, 2011), China (Yi et al., 2014), Bangladesh (Seraj et al., 1997), Vietnam (Nhuan et al., 2014), and Samoa (Grasso et al., 2014). The research methods used for urban vulnerability include data envelopment analysis (DEA), the geographic information system (GIS) ArcGIS, scenario analysis, the image-merging method, the vulnerability-functionbased method, etc. As that research has become more profound, urban vulnerability research has evolved from the assessment of vulnerability associated with natural environmental deterioration to the investigation of the impact of human activities on vulnerability. In addition, the related research has also evolved from the simple assessment and passive acknowledgment of vulnerability-associated damage to the social economy to the active exploration of countermeasures for either coping with or avoiding vulnerability. Moreover, the focus of urban vulnerability research has shifted from traditional concepts, such as urban hazard vulnerability and eco-environmental vulnerability, to new concepts that are more closely associated with coupled systems, such as human-environment and socioecological systems (Fang et al., 2007).

Urban vulnerability research emerged in China more than two decades later than in other countries. However, with the acceleration of China's rapid urbanization, chronic urban problems have become prominent, leading to an increasing number of urban vulnerability studies. According to the published data, China's vulnerability research primarily focused on eco-environmental vulnerability and hazard vulnerability, which has made great progress in assessing eco-environmental vulnerability (Cai et al., 2009), classifying vulnerable eco-environmental systems (Liu and Li., 2007), and assessing vulnerability to natural disaster (Liu et al., 2010). Since the 21 st century, scholars have attempted to investigate the socioeconomic vulnerability of a specific region under a specific disturbance, focusing on 
economic social vulnerability and sustainable development in special types of cities, including resource-based cities, coastal cities, and tourist cities ( $\mathrm{Su}$ et al., 2008). However, the related studies primarily evaluated only the vulnerability of a single urban subsystem. In recent years, researchers began to pay attention to the vulnerability of urban complex systems, such as the vulnerability of urban economic social systems (Zhao and Zhang, 2006), the vulnerability of human-environment systems (Tian et al., 2013), urban vulnerability and sustainable development (Holling, 2007), and the vulnerability of urban and regional development (Zhang, 2006). However, until now, only a relatively small number of studies on the above aspects have been conducted.

\subsection{Objectives and significance of this research}

Because of the complexity of cities and vulnerability concepts, studies in different fields have focused on different aspects of urban vulnerability. Consequently, the research content of urban vulnerability is scattered and relatively independent, leading to a lack of comparability among the research data and resulting in tremendous difficulties in summarizing the conclusions through comparison of independent research data (Wang, 2013). Therefore, from the perspective of sustainable development, this paper proposes a comprehensive concept of urban vulnerability; according to this concept, urban vulnerability refers to the coping capacity to resist multiple aspects of disturbances from various internal and external natural and human factors - e.g., resources, ecological environmental, economic, and social development-during the urban development process. A city is considered vulnerable if its anti-disturbance capacity is below a threshold level. Urban vulnerability is generally a collective reflection of four types of vulnerability, namely, resource vulnerability, eco-environmental vulnerability, economic vulnerability, and social vulnerability (Figure 1). Based on the proposed concept of urban vulnerability, we attempted to construct a research framework and a comprehensive assessment system of urban vulnerability. A nation-scale comprehensive assessment was performed to clarify the overall status and spatial distribution pattern of urban vulnerability in China and to explore vulnerability characteristics in cities of different sizes. This study tries to provide the government with scientific evidence for the formulation and perfection of related policies and regulations for reducing and coping with

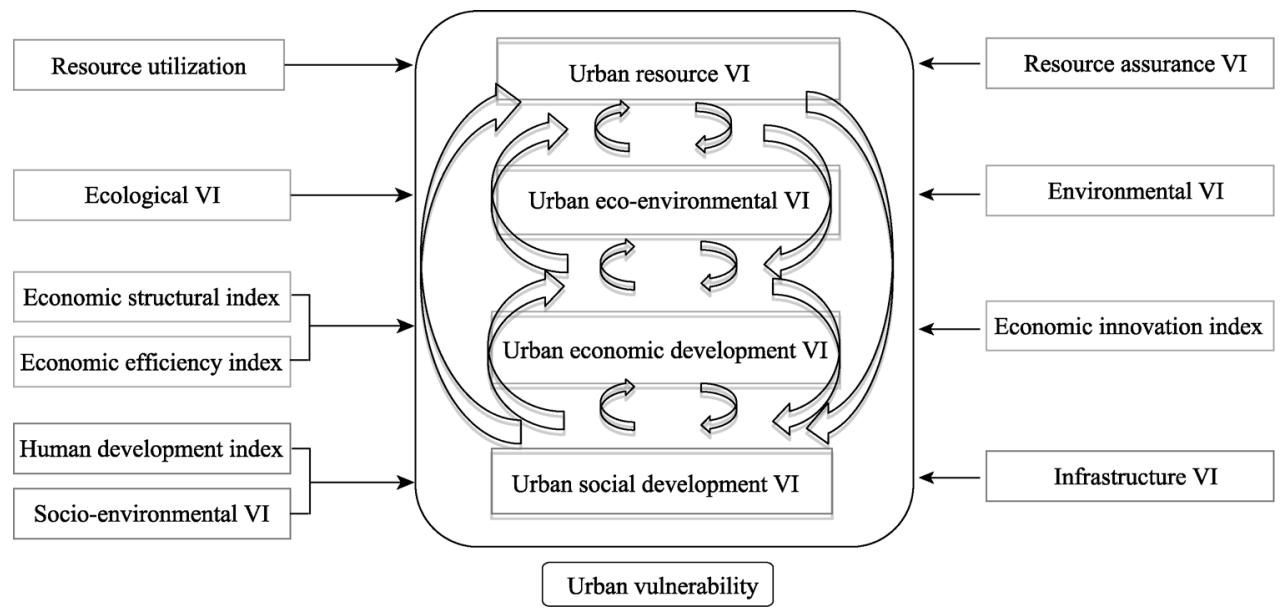

Figure 1 Basic framework for the urban vulnerability assessment 
urban vulnerability and for creating sustainable development.

\section{Study area and data sources}

According to 2011 China City Statistical Yearbook, China includes 288 prefecture-level cities $^{1}$. For the convenience of data acquisition, 288 prefecture-level cities make up the study area for this study. And Hong Kong SAR, Macao SAR, or Taiwan Province were not included in this study because the relevant data were incomplete.

The data used in the calculations detailed in this section were collected from China City Statistical Yearbook, China Regional Economic Statistical Yearbook, China Urban Construction Statistical Yearbook, China Water Resources Bulletin, national economy and society developed statistical bulletin, and the statistical yearbooks of each city for the relevant years of this study.

In a comprehensive assessment of urban vulnerability, to eliminate the influence of data dimensional and size differences on the calculation results, it is necessary to first standardize the raw data. Because of the differences in the effect of sustainable development, parameters should be standardized with different methods. According to the relationship characteristics of vulnerability, each parameter was standardized using a different formula. With respect to their attributes, the objective assessment parameters in the systemic assessment system can be divided into three types:

Positive parameters: a larger value indicates higher vulnerability. The function is

$$
X_{i}=\frac{x_{i}-x_{0}}{x_{0}}= \begin{cases}\left(x_{i}-x_{0}\right) / x_{0} & x_{i}>x_{o} \\ 0 & x_{i} \leqslant x_{o}\end{cases}
$$

Negative parameters: a larger value indicates lower vulnerability. The function is

$$
X_{i}=\frac{x_{o}-x_{i}}{x_{o}}= \begin{cases}\left(x_{o}-x_{i}\right) / x_{o} & x_{i}>x_{o} \\ 0 & x_{i} \leqslant x_{o}\end{cases}
$$

Optimal parameters: this type of parameter has an optimal value, and neither a higher value nor a lower value than this optimal level is considered more beneficial (Duan, 2005). The function is

$$
X_{i}=\frac{2\left(x_{i}-x_{o}\right)}{x_{o}}= \begin{cases}2\left(x_{o}-x_{i}\right) /\left(x_{\max }-x_{\min }\right) & x_{\min }<x_{i}<x_{o} \\ 0 & x_{i}=x_{o} \\ 2\left(x_{i}-x_{o}\right) /\left(x_{\max }-x_{\min }\right) & x_{o}<x_{i}<x_{\max }\end{cases}
$$

In the above functions, $X_{i}$ is the nondimensionalized value of $x_{i}$ of the 36 parameters, which reflects the dispersion degree of all the parameters included in the concept of urban vulnerability; $x_{i}$ is the statistical value of a parameter; $x_{0}$ is the standard value of a parameter; and $x_{\max }$ and $x_{\min }$ are the maximum and minimum values of the same parameter, respectively. $i$ indicates the $i$ th parameter in the equation, in which $i=1,2, \ldots, 36$ and $n=288$.

\footnotetext{
${ }^{1}$ In China, there are three types of cities: a municipality is a provincial-level division (e.g., Beijing); a prefecture-level city is governed by provinces or autonomous regions; and a county-level city is a sub-unit of a prefecture-level administrative division. Prefecture-level cities, the unit of analysis in this study, usually comprise an urban core surrounded by large stretches of rural areas. See Chan (2007) for an insightful discussion on the definition of cities in China and its implication on urbanization statistics.
} 


\section{Methods}

\subsection{The index system for a comprehensive assessment of urban vulnerability}

In this study, using 288 Chinese cities at the prefectural level and above as study subjects, an index system for a comprehensive assessment of urban vulnerability was established from four dimensions (urban resources, environment, economy, and society) that involved 36 corresponding parameters. Standard values of urban vulnerability parameters were determined using the following approaches: (1) directly adopting the standard values proposed in the international or national survey reports; (2) referencing the current actual values in the domestic and international advanced areas; (3) basing those values on the current calculation results; and (4) referencing the currently available data in authoritative literature. The weights of the urban vulnerability index (VI) and relevant parameters were calculated using the expert scoring method and analytic hierarchy process (AHP) with the support of entropy technology (Fang, 2000). Based on the obtained results, an index system and standard parameter values for comprehensive assessment of urban vulnerability were established (Table 1).

\subsection{The measurement model for the comprehensive assessment of urban vulnerability}

\subsubsection{The measurement model for subfactor indexes}

Urban subfactor VIe are listed in the criteria hierarchy, which can be calculated based on the arithmetic mean values of corresponding parameters using the below equation:

$$
U V I_{e}=\left(\sum_{i=1}^{m} X_{i}\right) / m
$$

where $X_{i}$ is the standardized value of a parameter, $m$ is the number of parameters included in a subfactor index, and $U V I_{e}$ is the subfactor index of urban vulnerability. There are 10 subfactor indexes, including urban resource utilization VI $(R U V I)$, urban resource assurance VI $(R T V I)$, urban ecological VI $(E C V I)$, urban environmental VI (ENVI), urban economic structure index $(E S I)$, economic efficiency index $(E E I)$, urban economic innovation index $(E I I)$, urban human development index $(H D I)$, urban infrastructure VI (IFVI), and urban social environmental VI $(S E V I)$.

\subsubsection{The measurement model for subsystem indexes}

Urban subsystem VIs are listed in the target hierarchy, which can be calculated using a weighting method following the below equation:

$$
U V I_{s}=\sum_{i=1}^{n}\left(U V I_{e}\right)_{i} W
$$

where $\left(U V I_{e}\right)_{i}$ is the subfactor VI; $n$ is the number of subfactors included in a subsystem VI; $W i$ is the weight of a subfactor in the criteria hierarchy; and $U V I_{S}$ is the urban subsystem VI, including resource VI (URVI), eco-environmental VI (UEnVI), economic VI (UEcVI), and social VI (USVI). Because the urban economic structure index $(E S I)$, economic efficiency index $(E E I)$, urban economic innovation index $(E I I)$, and urban human development index $(H D I)$ are negative parameters, they were calculated using the values of "1-ESI," "1-EEI," "1-EII," and " $1-H D I . "$ 
Table 1 Index system for the comprehensive assessment of urban vulnerability in China

\begin{tabular}{|c|c|c|c|c|c|c|}
\hline $\begin{array}{c}\text { Target } \\
\text { hierarchy }\end{array}$ & Weight & $\begin{array}{l}\text { Criteria hierar- } \\
\text { chy }\end{array}$ & Weight & Parameter hierarchy & Unit & $\begin{array}{l}\text { Stan- } \\
\text { dard } \\
\text { value }\end{array}$ \\
\hline \multirow{7}{*}{$\begin{array}{l}\text { Resource } \\
\text { vulner- } \\
\text { ability }\end{array}$} & \multirow{7}{*}{0.20} & & & & tons of standard & \\
\hline & & \multirow{4}{*}{$\begin{array}{l}\text { Resource utili- } \\
\text { zation } \mathrm{VI}^{\mathrm{a}}\end{array}$} & \multirow{4}{*}{0.0900} & Overall energy consumption per GDP & coal equivalent & 0.4 \\
\hline & & & & Water consumption per GDP & $(\mathrm{SCE}) / 10^{4}$ yuan & 30 \\
\hline & & & & Electricity consumption per GDP & $\mathrm{m}^{3} / 10^{4}$ yuan & 500 \\
\hline & & & & Construction land per GDP & $\begin{array}{l}\mathrm{kw}-\mathrm{h} / 10^{4} \text { yuan } \\
\mathrm{m}^{2} / 10^{4} \text { yuan }\end{array}$ & 7 \\
\hline & & \multirow{2}{*}{$\begin{array}{l}\text { Resource assur- } \\
\text { ance } \mathrm{VI}^{\mathrm{b}}\end{array}$} & \multirow{2}{*}{0.1100} & Capability to assure the use of water resources & - & 1 \\
\hline & & & & Capability to assure construction land use & - & 1 \\
\hline \multirow{8}{*}{$\begin{array}{c}\text { Eco-envir } \\
\text { onmental } \\
\text { vulner- } \\
\text { ability }\end{array}$} & \multirow{8}{*}{0.20} & \multirow{3}{*}{ Ecological VI ${ }^{\mathrm{c}}$} & \multirow{3}{*}{0.0718} & Green coverage ratio in built-up areas & $\%$ & 50 \\
\hline & & & & Forest coverage rate & $\%$ & 27 \\
\hline & & & & Aridity index ${ }^{\mathrm{d}}$ & - & 0.5 \\
\hline & & \multirow{5}{*}{$\begin{array}{c}\text { Environmental } \\
\mathrm{VI}^{\mathrm{e}}\end{array}$} & \multirow{5}{*}{0.1282} & Carbon emission per GDP & tons $/ 10^{4}$ yuan & 2.5 \\
\hline & & & & Ratio of days with good air quality & $\%$ & 100 \\
\hline & & & & Urban centralized wastewater treatment ratio & $\%$ & 100 \\
\hline & & & & Comprehensive utilization ratio of industrial solid waste & $\%$ & 100 \\
\hline & & & & Hazard-free treatment ratio of household garbage & $\%$ & 100 \\
\hline \multirow{7}{*}{$\begin{array}{c}\text { Economic } \\
\text { vulner- } \\
\text { ability }\end{array}$} & \multirow{7}{*}{0.30} & $\begin{array}{l}\text { Economic struc- } \\
\text { ture index (Yang }\end{array}$ & \multirow{3}{*}{0.0996} & Hoffman coefficient & $\%$ & 1.5 \\
\hline & & et al., 2008; & & Proportion of the increased value of tertiary industry in GDP & $\%$ & 50 \\
\hline & & $\begin{array}{l}\text { Fang and Liu, } \\
\text { 2008) }\end{array}$ & & Economic extroversion & $\%$ & 0.5 \\
\hline & & \multirow{2}{*}{$\begin{array}{l}\text { Economic effi- } \\
\text { ciency index }\end{array}$} & \multirow[b]{2}{*}{0.1098} & Input/output ratio & \multirow[b]{2}{*}{$\begin{array}{l}\% \\
-\end{array}$} & \multirow[b]{2}{*}{$\begin{array}{c}1 \\
0.6\end{array}$} \\
\hline & & & & $\begin{array}{l}\text { Asset-liability ratio of industrial enterprises above designated } \\
\text { size }^{f}\end{array}$ & & \\
\hline & & \multirow[b]{2}{*}{$\begin{array}{l}\text { Economic inno- } \\
\text { vation index }\end{array}$} & \multirow[b]{2}{*}{0.0906} & Proportion of R\&D investment in GDP & \multirow[b]{2}{*}{$\begin{array}{l}\% \\
\%\end{array}$} & \multirow[b]{2}{*}{$\begin{array}{c}1.75 \\
3\end{array}$} \\
\hline & & & & $\begin{array}{l}\text { Proportion of technology spending in local financial expen- } \\
\text { diture }\end{array}$ & & \\
\hline \multirow{15}{*}{$\begin{array}{c}\text { Social } \\
\text { vulner- } \\
\text { ability }\end{array}$} & \multirow{15}{*}{0.30} & \multirow{5}{*}{$\begin{array}{l}\text { Human devel- } \\
\text { opment index } \\
\text { (IMF, 2007; } \\
\text { Urban, 2004) }\end{array}$} & \multirow{5}{*}{0.1209} & Natural population growth rate & $\%$ & 8 \\
\hline & & & & Number of students in general middle schools per $10^{4}$ people & - & 500 \\
\hline & & & & Number of doctors per $10^{4}$ people & - & 30 \\
\hline & & & & Living space per capita & $\mathrm{m}^{2}$ & 30 \\
\hline & & & & Per capita GDP & $10^{4}$ dollars & 0.55 \\
\hline & & & & Number of mobile phones per 100 people & - & 100 \\
\hline & & & & Number of international internet households per 100 people $^{\mathrm{g}}$ & - & 75 \\
\hline & & & & Density of water supply pipe networks in built-up areas & $\mathrm{km} / \mathrm{km}^{2}$ & 15 \\
\hline & & Infrastructure VI & 0.1083 & Density of water drainage pipe networks in built-up areas & $\mathrm{km} / \mathrm{km}^{2}$ & 10 \\
\hline & & & & Average road area per capita & $\mathrm{m}^{2}$ & 15 \\
\hline & & & & Number of public buses/trolleys per $10^{4}$ people & - & 40 \\
\hline & & & & Urban-rural difference index & $\%$ & 0 \\
\hline & & Socio-environm & & Percentage of poverty population & $\%$ & 5 \\
\hline & & ental VI & 0.0708 & Registered urban/town unemployment percentage & $\%$ & 4 \\
\hline & & & & Social insurance coverage rate & $\%$ & 100 \\
\hline
\end{tabular}

Note: ${ }^{\text {a }}$ Energy consumption per Gross Domestic Product (GDP) was 1.01 tons of SCE/ $10^{4}$ yuan in China, with the lowest rate in Beijing ( 0.46 tons of SCE $/ 10^{4}$ yuan) in 2011 ; the standard value was set as 0.4 tons of SCE/10 4 yuan according to related research. In 2011 , water consumption per GDP was $15.02 \mathrm{~m}^{3} / 10^{4}$ yuan in China, where Ordos had the lowest consumption of $3.17 \mathrm{~m}^{3} / 10^{4}$ yuan; Japan's rate was approximately $25 \mathrm{~m}^{3} / 10^{4}$ yuan; the standard value was set as $30 \mathrm{~m}^{3} / 10^{4}$ yuan in this study. Electricity consumption per GDP ( $10^{4}$ yuan) was $567.95 \mathrm{kw} \mathrm{h} / 10^{4}$ yuan globally, with $997.23 \mathrm{kw} \mathrm{h} / 10^{4}$ yuan in China, where the lowest consumption was in Qingyang $\left(216.67 \mathrm{kw} \mathrm{h} / 10^{4}\right.$ yuan); the standard value was set as $500 \mathrm{kw} \mathrm{h} / 10^{4}$ yuan. The land area for construction use per GDP (10 4 yuan) was $13.03 \mathrm{~m}^{2} / 10^{4}$ yuan in China, with the lowest amount used in Dongguan $\left(2.13 \mathrm{~m}^{2} / 10^{4}\right.$ yuan); the standard value was set as $7 \mathrm{~m}^{2} / 10^{4}$ yuan in this study.

${ }^{\mathrm{b}}$ Based on the consideration of the threshold for resource exploration and utilization, the standard value for water resource assurance was set as 1 according to the related study (Fang and Wang, 2011), which indicates that the production capability is at a level where the need for urbanization development can be met without disruption of the ecological balance. The standard value for the assurance of construction land use was set as 1 , which indicates that the city has sufficient developmental potential.

${ }^{\mathrm{c}}$ Related studies have demonstrated that green coverage of more than $50 \%$ can maintain a satisfactory urban eco-environment. Some domestic scholars have adopted a standard value of 55\% for the green coverage ratio in built-up areas (Ye, 2001). In 2011, China's urban green coverage ratio in built-up areas was $40 \%$. In this study, we set the standard value of a $50 \%$ urban green coverage ratio in built-up areas based on comprehensive consideration. Using a land area of $100 \mathrm{~m}^{2}$ for construction use per capita for the calculation, the standard value of the green land area per capita was determined to be $30 \mathrm{~m}^{2}$. Considering that the world's average forest coverage ratio 
is currently $27 \%$, we set the forest coverage ratio as $27 \%$.

d The aridity index reflects an area's water balance and thermo balance. A higher aridity index indicates a more vulnerable eco-environment (Huang et al., 2006). Because of the large study area and the resulting difficulties in acquiring relevant data in this study, the areas of different aridity levels in China were assigned with corresponding numbers; that is, humid area $=0$, semi-humid area $=0.3$, semi-arid area $=0.6$, and arid area $=1$. The standard value was set as 0.5 .

${ }^{\mathrm{e}}$ The standard value of the air quality index was $100 \%$ and was temporarily set at $80 \%$ for a moderately prosperous society according to the modernization research of the Chinese Academy of Social Sciences; thus, we set the national target value as $100 \%$. In 2008 , the standard value for the wastewater treatment ratio, hazard-free treatment ratio of household garbage, and comprehensive utilization ratio of solid waste was $100 \%$. The volume of carbon emissions per GDP ( $10^{4}$ yuan) in China was 2.5 tons in 2011 ; thus, the standard value was set as 2.5 tons $/ 10^{4}$ yuan in this study.

${ }^{\mathrm{f}}$ Because of the difficulties in acquiring data regarding the urban liability ratio, the asset-liability ratio of urban industrial enterprises above a designated size was used to substitute the urban liability ratio, of which the standard value was set as 0.6 , pursuant to the related literature.

${ }^{\mathrm{g}}$ The average number of Internet-connected households per 100 people is 30.15 in the world, 73.4 in high-income countries, 74.25 in the United States, 77.64 in Japan, and 25.1 in China (where Shenzhen has the highest number, 104.71); thus, the standard value was set as 75. As required in the Regulations for Urban-Rural Planning, the average road area per capita is $7-15 \mathrm{~m}^{2}$ (China, 2008), and this paper uses $15 \mathrm{~m}^{2}$ as a standard value. The standard value of the number of public buses/trolleys per $10^{4}$ people in 2011 was set as 42 .

\subsubsection{The measurement model for comprehensive assessment}

Urban comprehensive VI was calculated using the weighted summation of urban subsystem VIs following the below equation:

$$
U V I=\sum_{i=1}^{p}\left(U V I_{s}\right)_{i} Q_{i}
$$

where $\left(U V I_{S}\right)_{i}$ is the subsystem VI, $Q_{i}$ is the weight of each subsystem in the target hierarchy, $p$ is the number of subsystem indexes included in the comprehensive VI, and UVI is the urban comprehensive VI.

\subsection{Determination and grading of urban vulnerability}

Based on the calculated values, urban comprehensive VI (UVI) was separated into five grades according to the natural breaking points, that is, lower vulnerability, low vulnerability, moderate vulnerability, high vulnerability, and higher vulnerability (Table 2).

Table 2 Grading criteria for the comprehensive assessment of urban vulnerability in China

\begin{tabular}{cccccc}
\hline $\begin{array}{c}\text { Grades of } \\
\text { urban } \\
\text { vulnerability }\end{array}$ & Grade I & Grade II & Grade III & Grade IV & Grade V \\
\cline { 2 - 6 } & $\begin{array}{c}\text { Lower } \\
\text { vulnerability }\end{array}$ & $\begin{array}{c}\text { Low } \\
\text { vulnerability }\end{array}$ & $\begin{array}{c}\text { Moderate } \\
\text { vulnerability }\end{array}$ & $\begin{array}{c}\text { High } \\
\text { vulnerability }\end{array}$ & $\begin{array}{c}\text { Higher } \\
\text { vulnerability }\end{array}$ \\
\hline$U V I$ & $<0.47$ & $0.48-0.52$ & $0.53-0.57$ & $0.58-0.62$ & $>0.63$ \\
\hline
\end{tabular}

\section{Results}

\subsection{Urban vulnerability demonstrates a remarkable "grade-difference"-based differ- entiation feature, and overall vulnerability is moderate}

The average $U V I$ of 288 Chinese cities at the prefectural level and above is 0.5481 , and their overall vulnerability is moderate. Shenzhen has the lowest $U V I$ of 0.1221 , followed by Beijing's urban UVI of 0.3622 . Baiyin City, a city facing resource exhaustion, has the highest $U V I, 0.6762$. There are remarkable differences in UVI among individual cities, as evidenced by the data indicating that the highest value is more than five times the lowest value. According to the UVI, urban vulnerability was divided into five grades based on the natural 
breaking points. The average UVIS of the five grades of cities are $0.4239,0.5005,0.5514$, 0.5940 , and 0.6462 , and the average $U V I$ of the high-vulnerability cities is 2.9 times the average $U V I$ of the low-vulnerability cities, indicating distinct differences among cities at different vulnerability grades.

The hierarchical analysis of the number of cities demonstrated that the numbers of cities with low vulnerability, moderate vulnerability, and higher vulnerability are relatively large, accounting for $19.79 \%, 42.36 \%$, and $26.04 \%$ of the total number of cities, respectively, and the sum of the cities at these three vulnerability grades accounted for $88.19 \%$ of the total number of cities. The numbers of the lower-vulnerability cities and the higher-vulnerability cities are comparable at 20 and 14, accounting for $7 \%$ and $5 \%$ of the total number of cities, respectively. In China, urban vulnerability shows a "more in the middle and fewer at the ends" distribution pattern. Various problems arose during rapid urbanization, and the cities have shown vulnerability to different extents.

\subsection{Urban vulnerability demonstrates a "gradient-distribution"-based heterogeneous feature, as demonstrated by the higher urban vulnerability in the eastern region than in the central-western regions}

The cities with lower or low vulnerability are mostly located in the eastern coastal zone, the moderate-vulnerability cities are mostly located in Central China, and the cities with high or higher vulnerability are mostly located in Western China. In terms of overall urban vulnerability, a statistical analysis of cities with different grades of vulnerability in Eastern, Central, and Western China ${ }^{2}$ revealed significant interregional differences. The average UVI of the cities in Eastern, Central, and Western China is 0.5161, 0.5564 and 0.5911, respectively. In terms of the vulnerability grades, cities with Grade I and Grade II vulnerability were concentrated in the east and accounted for more than half of China's cities with the same grade $(85.00 \%$ and $68.42 \%$, respectively).A larger number of cities with Grade III and Grade IV vulnerability are distributed in Central China and accounted for $52.46 \%$ and $37.33 \%$ of those cities, respectively. The Grade V cities are concentrated in the west(Figure 2). The analysis of the proportion of cities with different grades of vulnerability in each region shows that the proportion of Grade III cities (40.86\%) is the largest in Eastern China, followed by Grade II and Grade I, and Grade $\mathrm{V}$ cities are scarce in the east. Central China is dominated by Grade III and Grade IV cities, which account for $58.71 \%$ and $25.69 \%$, respectively. Western China is dominated by Grade IV and Grade V cities, which account for $56.25 \%$ and $18.75 \%$, respectively (Figure 3).

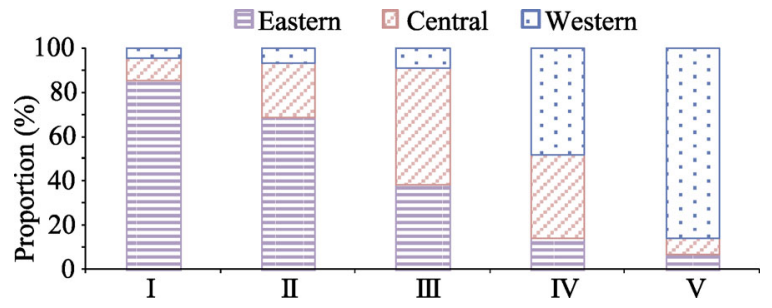

Figure 2 Distribution of cities with different grades of vulnerability in Eastern, Central, and Western China

\footnotetext{
2 The region to which a city belongs is determined based on the region to which the corresponding provinces (or autonomous regions or municipalities directly under the Central Government) belongs. Eastern China includes Liaoning, Hebei, Beijing, Tianjin, Shandong, Jiangsu, Shanghai, Zhejiang, Fujian, Guangdong, and Hainan (11). Central China includes Heilongjiang, Jilin, Shanxi, Henan, Anhui, Hubei, Hunan, and Jiangxi (8). Western China includes Inner Mongolia, Shaanxi, Gansu, Ningxia, Qinghai, Xinjiang, Sichuan, Yunnan, Guizhou, Tibet, Chongqing, and Guangxi (12).
} 
Interregional differences are also demonstrated by Figure 4, in which urban vulnerability shows a westbound increasing trend. Moreover, urban resource vulnerability, eco-environmental vulnerability, economic vulnerability, and social vulnerability all show spatial differentiation consistent with that of

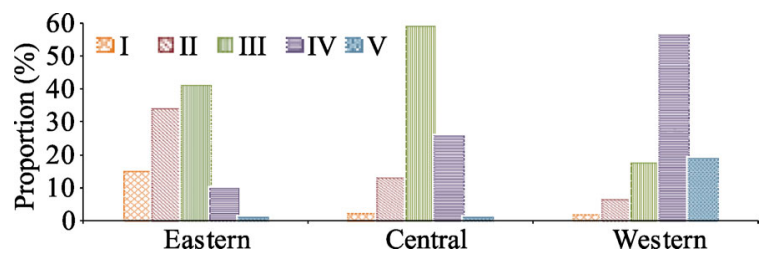

Figure 3 Proportions of cities with different grades of vulnerability in Eastern, Central, and Western China urban overall vulnerability, showing a low-to-high order of Eastern China $<$ Central China $<$ Western China (Figure 5). In particular, there is a large difference in the vulnerabilities of resource utilization, environmental protection, and infrastructure (Table 3 ).

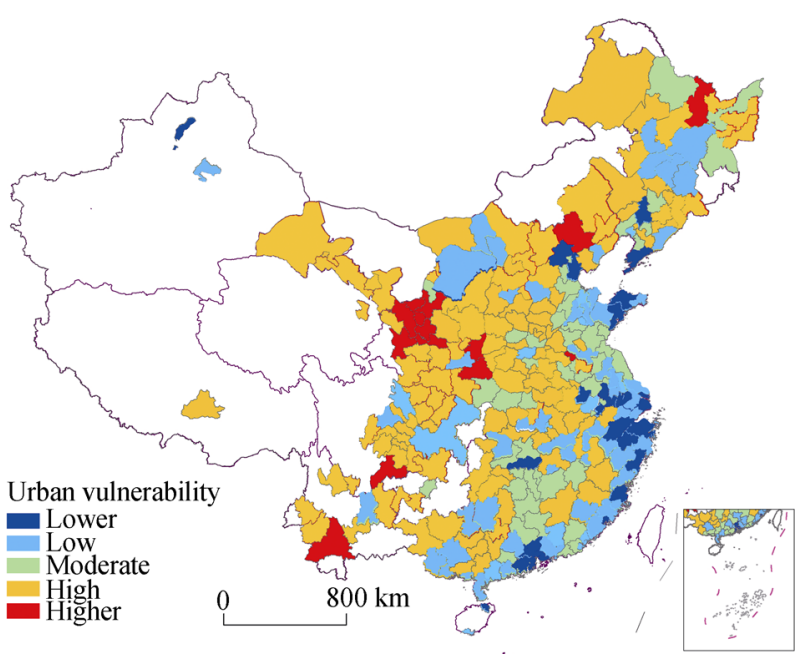

Figure 4 The spatial differentiation of urban synthetic vulnerability in China
The spatial "gradient-distribution"-based heterogeneous feature of China's urban vulnerability results from the impacts of multiple factors, both historical and environmental. From the perspective of natural conditions, compared to Eastern China, Western China has much poorer water and soil resources and climate conditions: the surface vegetation is mostly distributed among steppe and desert, and geologic and topographic features are complicated. In Western China, natural disasters frequently occur, environmental conditions are poor, and the eco-environment is vulnerable. These disadvantageous conditions are not conducive to human habitation and agricultural production, resulting in a poverty situation that has long existed in the region. Since the implementation of the reformation and opening-up policy, China's unbalanced development strategy has drastically promoted the rapid growth of Eastern China, making this region a new economic growth point but further broadening the gap in economic development between the eastern and central-western regions. Moreover, differences in economic development have led to increased interregional differences in social development, such as education, medical care, and infrastructure. Since 2000, with the implementation of the Development Campaign of the Western Regions, economic growth in Western China has significantly accelerated, along with essential improvement in urban and rural living standards, along with education and infrastructure status. However, against the background of nationwide rapid economic growth, particularly that of Eastern China, the difference between the eastern and western regions did not decrease and instead increased in some aspects. During the period from 1979 to 2001, Eastern China contributed 57.8\% and Central China contributed 27.9\% toward GDP, whereas Western China contributed only $14.3 \%$. Taken together, differences in natural conditions led to differences in economic development, and differences in the total economy and economic development 
led to differences in demographic and social development. Through this process, the combined effects of natural, economic, and social factors resulted in the spatial heterogeneous characteristics of urban vulnerability.

(a) Urban resource vulnerability

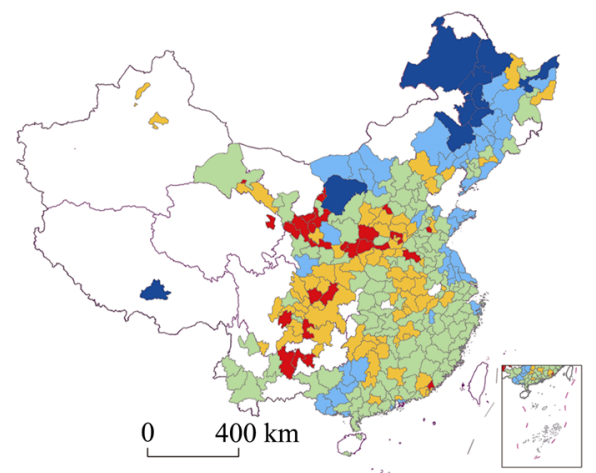

(c) Urban economic vulnerability

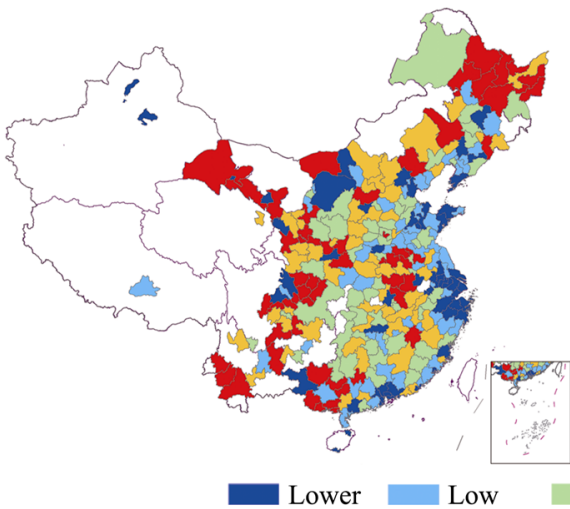

(b) Urban eco-environmental vulnerability

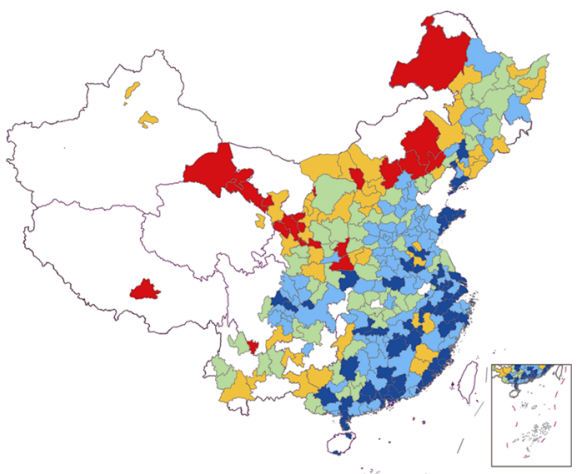

(d) Urban social vulnerability

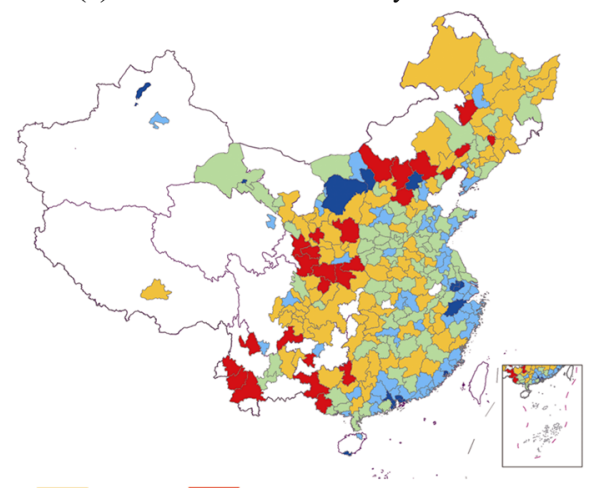

Figure 5 Spatial heterogeneous distribution of urban resource vulnerability, eco-environmental vulnerability, economic vulnerability, and social vulnerability in China

Table 3 Comparison of the assessment indexes of urban vulnerability in Eastern, Central, and Western China

\begin{tabular}{ccccccccccccc}
\hline Region & \multicolumn{2}{c}{$\begin{array}{c}\text { Resource Resource Ecological } \\
\text { utilization } \\
\text { VI }\end{array}$} & $\begin{array}{c}\text { VI } \\
\text { VI }\end{array}$ & $\begin{array}{c}\text { Environ- } \\
\text { mental } \\
\text { VI }\end{array}$ & $\begin{array}{c}\text { protection } \\
\text { VI }\end{array}$ & $\begin{array}{c}\text { Economic } \\
\text { structure } \\
\text { index }\end{array}$ & $\begin{array}{c}\text { Economic } \\
\text { efficiency } \\
\text { index }\end{array}$ & $\begin{array}{c}\text { Economic } \\
\text { innovation } \\
\text { index }\end{array}$ & $\begin{array}{c}\text { Human } \\
\text { develop- } \\
\text { ment index }\end{array}$ & $\begin{array}{c}\text { Socio-en } \\
\text { viron- } \\
\text { mental } \\
\text { VI }\end{array}$ & $\begin{array}{c}\text { Infra- } \\
\text { structure } \\
\text { VI }\end{array}$ \\
\hline Eastern China & 0.0798 & 0.0338 & 0.0202 & 0.0144 & 0.0307 & 0.0653 & 0.0490 & 0.0339 & 0.0368 & 0.0388 \\
Central China & 0.1256 & 0.0348 & 0.0221 & 0.0215 & 0.0440 & 0.0734 & 0.0619 & 0.0349 & 0.0379 & 0.0501 \\
Western China & 0.1586 & 0.0409 & 0.0281 & 0.0340 & 0.0452 & 0.0792 & 0.0697 & 0.0383 & 0.0490 & 0.0571 \\
\hline
\end{tabular}

\subsection{Urban vulnerability distribution shows a remarkable clustered spatial differen- tiation, and areas with concentrated cities have lower vulnerability than other areas}

In Figure 4, the blank areas indicate the absence of cities at a prefectural level and above, such as autonomous prefectures. As shown in this figure, cities with low urban vulnerability are concentrated, showing a "clustered" distribution pattern. The areas with low urban vulnerability include the Harbin-Changchun area, the central and southern Liaoning area, the Beijing-Tianjin-Hebei area, the Shandong Peninsula, the Yangtze River Delta, the Pearl River Delta, the middle Yangtze River area, the western Taiwan Straits, and the 
Chengdu-Chongqing area. This distribution pattern is consistent with the spatial distribution of the major city clusters in China (Figure 6). In the areas with a clustered distribution, cities with a low UVI and low vulnerability include Changchun and Harbin (in the Harbin-Changchun area); Shenyang and Dalian in the central and southern Liaoning area; Beijing and Tianjin (in the Beijing-Tianjin- Hebei area); Qingdao, Yantai, and Jinan (in the Shandong Peninsula); Shanghai, Nanjing, Wuxi, Ningbo, Yangzhou,

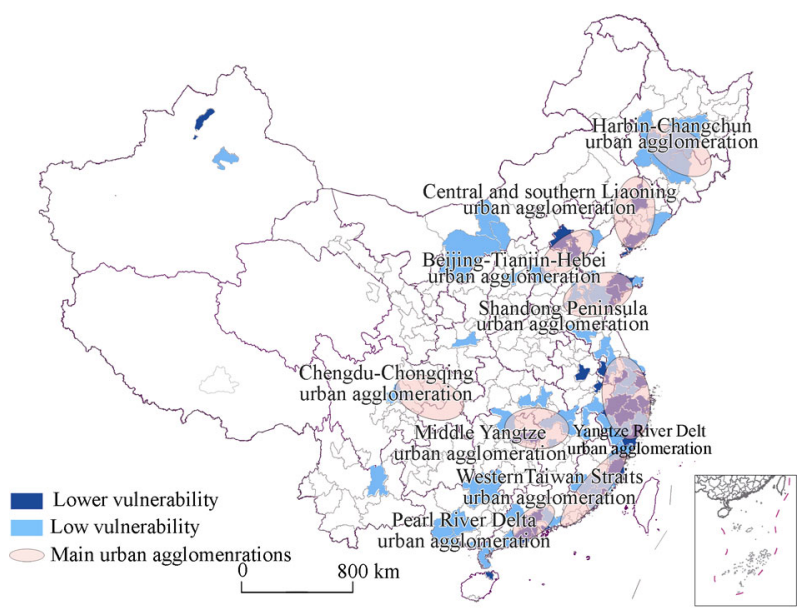

Figure 6 Distribution of cities with lower or low vulnerability

Suzhou, Changzhou, Taizhou, Zhoushan, and Zhenjiang (in the Yangtze River Delta); Shenzhen, Zhuhai, Xiamen, Guangzhou, Zhongshan, and Dongguan (in the Pearl River Delta); Wuhan and Changsha (in the middle Yangtze River area); Fuzhou and Xiamen (on the western Taiwan Straits); and Chengdu and Chongqing (in the Chengdu-Chongqing area). Clearly, the cities with lower or low vulnerability are mostly distributed within the

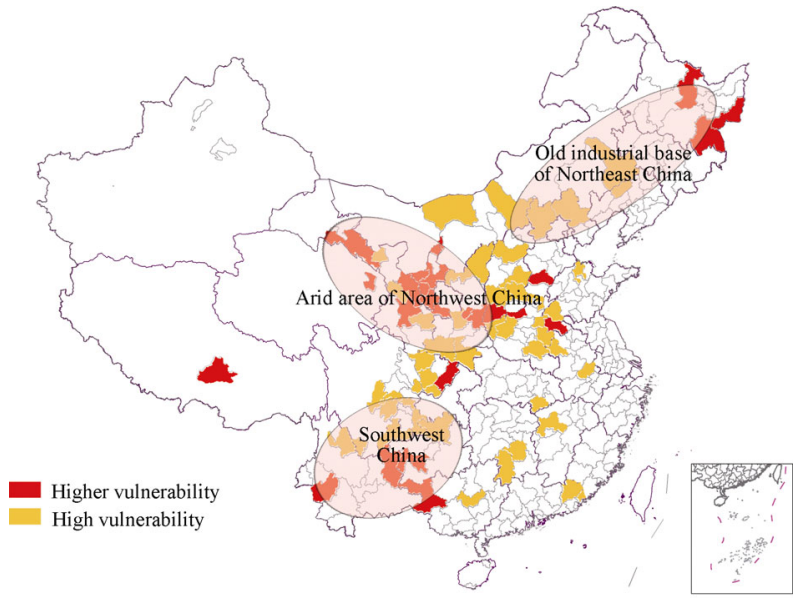

Figure 7 Distribution of the cities with high or higher vulnerability city-cluster areas of Eastern China, and only a few are capital or major cities of the provinces in centralwestern China. Cities with high or higher vulnerability are primarily concentrated in the old industrial base of northeast China, the arid area of northwest China, and the southwest China (Figure 7). Developing and expanding city clusters are not only a major method of reducing urban vulnerability but are also an important approach to promoting healthy urbanization and improving the developmental level of urbanization.

\subsection{Degree of urban vulnerability is associated with city size to a certain extent, and larger cities are less vulnerable}

Using the metropolitan population as an indicator of city size, the relationship between city size and urban vulnerability was explored. From the perspective of individual cities (Figure 8), there is no definitive corresponding relationship observed between urban vulnerability and city size; that is, UVI does not significantly decrease with the increasing metropolitan population. However, if cities are divided into different levels based on metropolitan population, the average $U V I$ s of small cities (below 200,000), medium-sized cities (200,000-500,000), 
large cities (500,000-1000,000), very large cities (1-2 million), and super-large cities (more than 2 million) are $0.5717,0.5697,0.5625,0.5461$, and 0.4903 , respectively, demonstrating a decreasing trend with increasing city size (Figure 9). However, the UVI differences among the small cities, medium-sized cities, and large cities are insignificant, whereas the difference between very large cities and small cities is relatively large. In other words, from the perspective of individual cities, larger cities do not necessarily have lower vulnerability, and both medium-sized and small cities are suitable for economic development and human life. Nevertheless, overall, the bigger the city size, the lower the urban overall vulnerability, which is conducive to urban sustainable development.

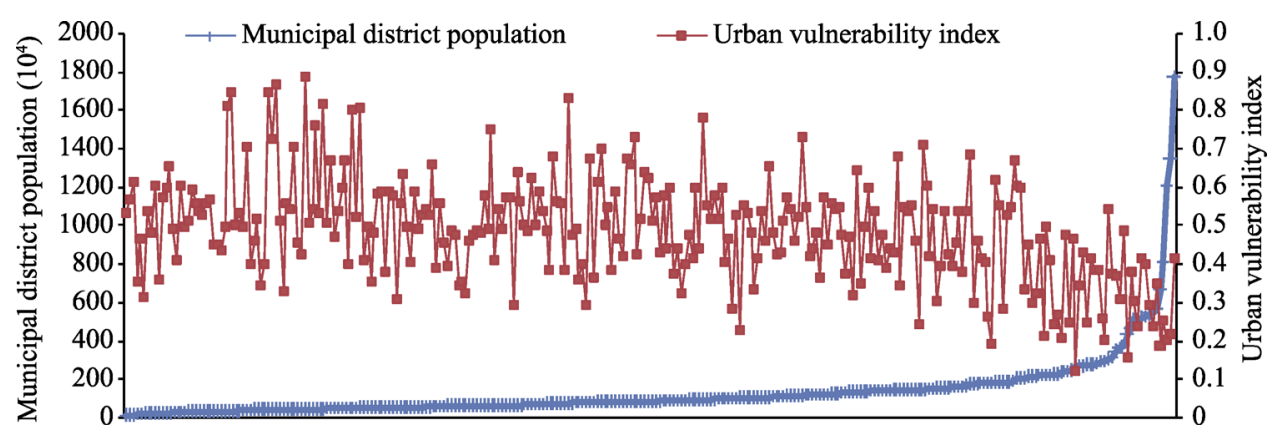

Figure 8 Relationship between city size and urban vulnerability in China

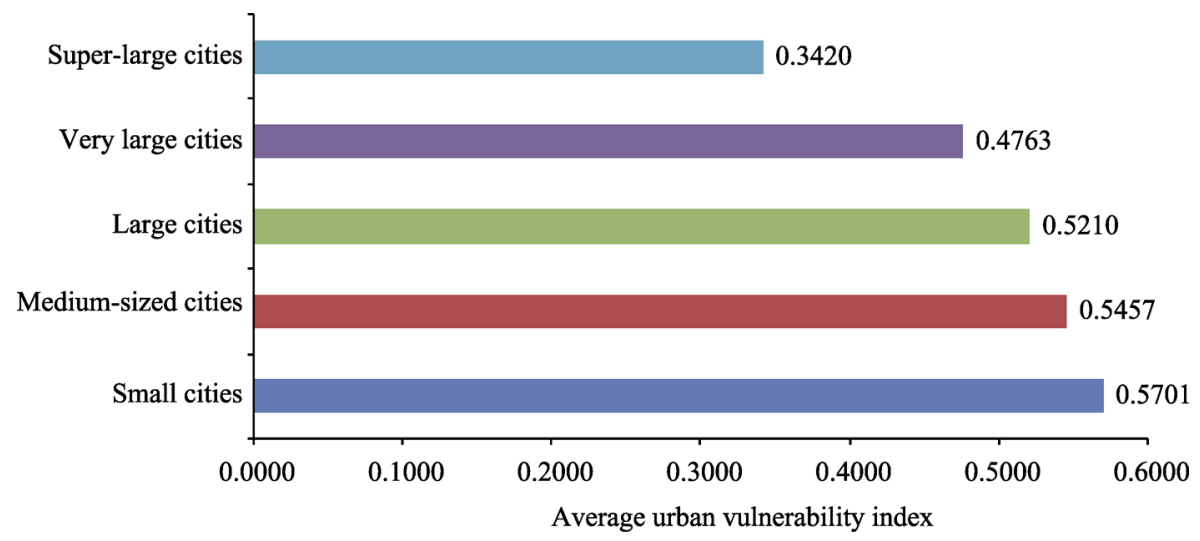

Figure 9 Average UVIS of cities with different sizes in China

\subsection{Resource-based cities have significantly higher vulnerability than comprehensive cities, and cities with a higher functional comprehensiveness have lower urban vulner- ability}

China's cities at a prefectural level and above were divided into two classes according to their urban functions: resource-based cities and comprehensive cities ${ }^{3}$. The average UVI is

\footnotetext{
${ }^{3}$ As reported in "A Survey on Economic Structural Transformation of Resource-Based Cities in China," published in 2002 by the Academy of Macroeconomic Research, State Development Planning Commission, China has 118 resource-based cities, including 47 prefectural-level cities and 71 county-level cities. Based on these data, the cities at a prefectural level and above in China can be roughly divided into two categories: resource-based cities and comprehensive cities. China has 47 resource-based cities and 241 comprehensive cities.
} 
0.5703 among the resource-based cities and 0.5440 among the comprehensive cities. Based on the grading criteria of the comprehensive assessment system of urban vulnerability, the resource-based cities overall have a relatively high vulnerability, whereas the comprehensive cities overall have a moderate vulnerability. In terms of resource types, the resource-based cities are further divided into coal-based cities, nonferrous-metallurgical-industry-based cities, ferrous-metallurgical-industry-based cities, petroleum-based cities, logging-industrybased cities, and other types of cities. The average UVIS of cities with different types of resources are in the descending order of coal-based cities $>$ metallurgical-industry-based cities $>$ logging-industry-based cities $>$ other types of cities $>$ petroleum-based cities (Figure 10). Moreover, compared with the comprehensive cities, the resource-based cities have significantly higher UVIS. In addition, among the resource-based cities, cities with different resource types have different vulnerability levels, and cities with a single type of resource are more vulnerable than cities with multiple types of resources.

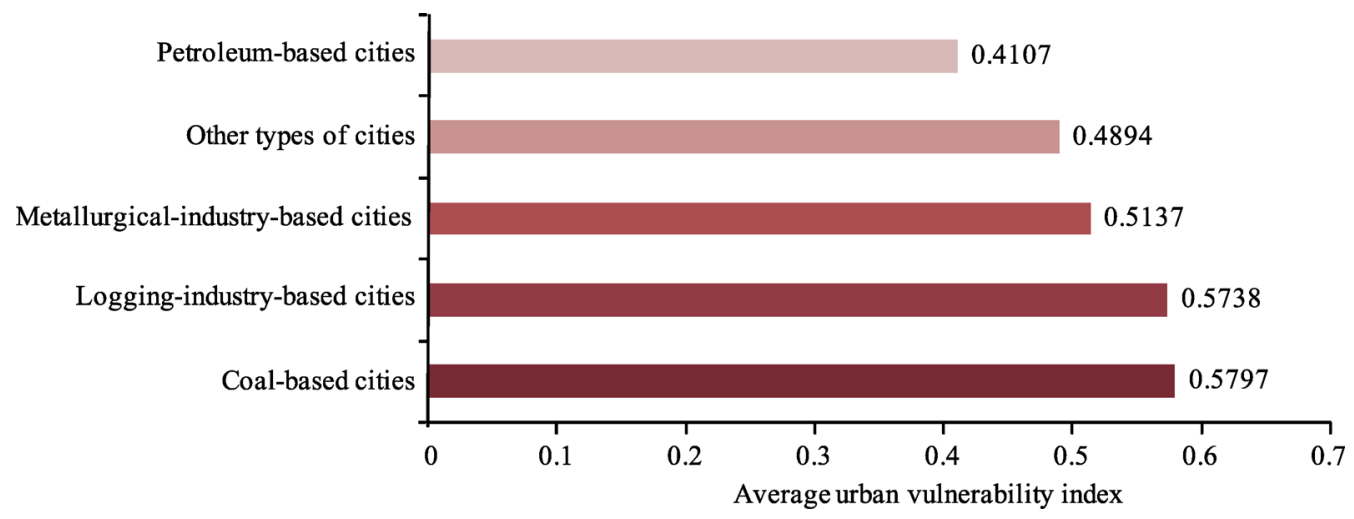

Figure 10 Average UVIs of different types of resource-based cities in China

\subsection{The economic growth rate of cities does not necessarily correspond to the level of urban vulnerability, and cities with rapid economic growth might not have low vul- nerability}

To explore the relationship between urban economic growth and vulnerability, the metropolitan GDP growth rate was used as an indicator of cities' economic growth. The GDP growth rate in 2011 was the slowest in Karamay City (3.5\%), followed by Langfang (4.0\%), whereas Qingyang had the fastest growth (30.3\%), followed by Wuzhou (27.1\%). Correspondingly, the urban VIs of these four cities is $0.4653,0.5300,0.5583$, and 0.5550 . Regardless of the large differences in the GDP growth rate among these four cities, their UVIS are not significantly different, indicating that economic growth does not necessarily correspond to the level of urban vulnerability. In addition, as shown in Figure 11, urban UVI irregularly fluctuates and does not decrease with the increase of the metropolitan GDP growth rate, suggesting that there is not necessarily a connection between the two. The correlation coefficient is only 0.15 , indicating a low correlation between the two. Therefore, cities' economic growth rate cannot reflect the level of urban vulnerability. 


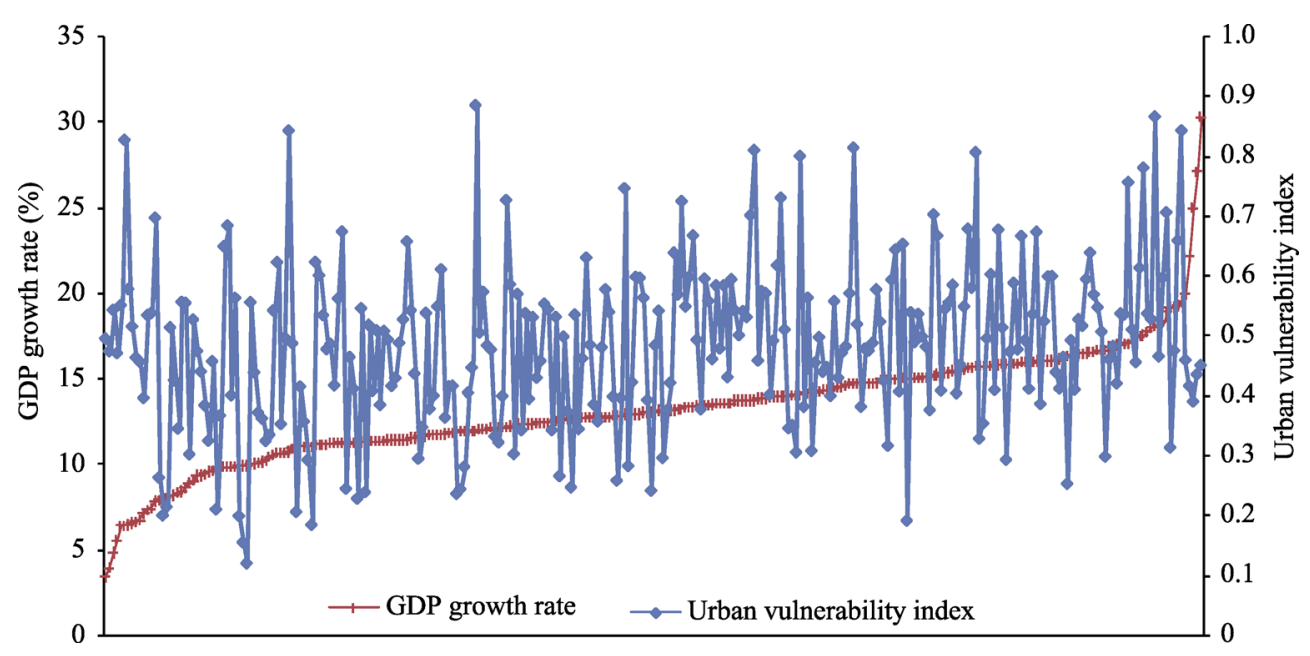

Figure 11 Relationships between urban vulnerability and economic growth in China

\section{Conclusions}

China is at a key historical stage of accelerating urbanization and improving the developmental quality of urbanization. Because the population is increasingly concentrated in cities and various "chronic urban diseases" are entering a saltation and high-incidence period, research on comprehensively measuring and assessing urban vulnerability is of great realistic significance. Such research is not only an important scientific tool to explore harmonious coexistence in the human-environment system but also meets the requirement for improving the developmental quality of urbanization against a new background of urbanization development.

(1) Urban vulnerability is a type of "chronic urban disease." With the passage of time, the chronic deposition effect will be amplified to form a "cumulative" effect and a cumulative magnifying effect. Once this chronic cumulative and amplifying process leads to the vulnerability exceeding a certain threshold level, the city will be separated from sustainable development conditions, resulting in a gradual increase in vulnerability, which can be instantly amplified when "catalyzed" by external interfering factors, leading to an accelerated magnifying effect and even a saltation effect. Once a "critical stage" has been entered, if no action is taken to reverse the situation, this "chronic urban disease" can cause a crash of the entire urban system. The concept of "urban vulnerability" consists of urban resource vulnerability, urban eco-environmental vulnerability, urban economic vulnerability, and urban social vulnerability.

(2) This study constructed a comprehensive assessment system of urban vulnerability. Based on the existing research, we proposed a concept of urban vulnerability from the perspective of sustainable development based on the theory of coupled resources of environmental, economic, and social systems. Furthermore, a comprehensive measurement and assessment model of urban vulnerability was established.

(3) China's urban vulnerability demonstrates a remarkable "grade-difference"-based heterogeneous characteristic, and overall, China's cities have moderate vulnerability. All the components of resource vulnerability-eco-environmental vulnerability, economic vulner- 
ability, and social vulnerability - demonstrate significant interregional differences. In terms of urban vulnerability differences, urban vulnerability in China was divided into five grades (lower vulnerability, low vulnerability, moderate vulnerability, high vulnerability, and higher vulnerability) based on their natural breaking points.

(4) China's urban vulnerability demonstrates a remarkable spatial heterogeneity, showing a pattern of "gradient distribution" and "clustered distribution." Urban vulnerability in Eastern China is significantly higher than in Western China, and areas with concentrated cities are significantly less vulnerable than other areas. Both urban overall vulnerability and subsystem vulnerabilities (i.e., resource vulnerability, eco-environmental vulnerability, and economic vulnerability, etc.) demonstrate an uneven distribution pattern with an increasing trend from the eastern coastal area to the northwestern inland area.

(5) Urban vulnerability has a corresponding relationship with city size and urban functions. Larger cities have a relatively lower vulnerability, resource-based cities have a higher vulnerability than comprehensive cities, and cities with a higher functional comprehensiveness have relatively lower vulnerability. Therefore, it is necessary to actively guide urban development and to formulate scientific policies for reasonable control of the urban developmental scale. In addition, multiplicity and comprehensiveness of urban functions should be emphasized; in particular, vulnerability mitigation for resource-based cities can be achieved only after transformation.

(6) No notable relationship between urban economic growth rate and vulnerability was observed. Cities with high economic growth do not necessarily have a low UVI. Thus, it is unreasonable to determine a city's vulnerability level based on its economic growth rate.

(7) The purpose of this study was to address questions about how to scientifically measure overall urban vulnerability and how to cope with and regulate urban vulnerability. We attempted to explore methods and countermeasures for determining and reducing urban vulnerability through the establishment of a comprehensive index model. However, due to the limited number of studies on overall urban vulnerability and the difficulties pertaining to the acquisition of statistical data and information, we accomplished only a static horizontal comparison of urban vulnerability among China's cities at the prefectural level and above. The dynamic vertical evolving process of urban vulnerability will be investigated in another study. Future research will focus on coping and regulatory control strategies related to urban vulnerability.

\section{References}

Abbas EL-Zein, Fahim N T, 2015. Assessment of vulnerability to climate change using a multi-criteria outranking approach with application to heat stress in Sydney. Ecological Indicators, 48(8): 207-217.

Adger W N, Brooks N, Bentham G, Agnew, Eriksen S, 2004. New Indicators of Vulnerability and Adaptive Capacity. Norwich:

Tyndall Centre for Climate Change Research (Technical Report No.7).

Adger W N, 2006. Vulnerability. Global Environmental Change, 16(3): 268-281.

Adrianto L, Matsuda Y, 2002. Developing economic vulnerability indices of environmental disasters in small island regions. Environmental Impact Assessment Review, 22: 393-414.

Birkmann J, 2007. Risk and vulnerability indicators at different scales: applicability, usefulness and policy implications. Environmental Hazards, 7(1): 20-31.

Burton I, Kates R W, White G F, 1978. The Environment as Hazard. New York: Oxford University Press. 
Cai Haisheng, Liu Musheng, Chen Meiqiu et al., 2009. Dynamic evaluation of ecological frangibility of Jiangxi Province based on GIS. Bulletin of Soil and Water Conservation, 29(5): 190-196. (in Chinese)

Chambers R, 1989. Editorial introduction: Vulnerability, coping and policy. Institute of Development Studies Bulletin, $20(2)$ : 1-7.

Chan K W, 2007. Misconceptions and complexities in the study of China's cities: Definitions, statistics, and implications. Eurasian Geography and Economics, 48: 383-412.

Chinese Architecture Bookstore LLC, 2008. National Urban Planning Norms. Beijing: China Building Industry Press. (in Chinese)

Cutter S L, 1996. Vulnerability to environmental hazards. Progress in Human Geography, 20(4): 529-539.

Cutter S L, Boruff B J, Shirley W L, 2003. Social vulnerability to environmental hazards. Social Science Quarterly, 84(2): $242-261$.

Duan Zhe, 2005. Regional sustainable development evaluation index system and comprehensive evaluation. Technoeconomics \& Management Research, (3): 27-28. (in Chinese)

Fang Chuanglin, 2000. The Regional Development Planning. Beijing: Science Press. (in Chinese)

Fang Chuanglin, 2009. Issues of resources and environment protection in China's rapid urbanization process and suggestions on countermeasures. Bulletin of Chinese Academy of Sciences, (5): 468-474. (in Chinese)

Fang Chuanglin, Liu Xiaoli, Lin Xueqin, 2008. Stages correction and regularity analysis of urbanization course of China. Arid Land Geography, 31(4): 512-523. (in Chinese)

Fang Chuanglin, Wang Deli, 2011. Comprehensive measures and improvement of Chinese urbanization development quality. Geographical Research, 30(11): 1931-1946. (in Chinese)

Fang Xiuqi, Yin Peihong, 2007. Review on the three key concepts of resilience, vulnerability and adaptation in the research of global environmental change. Progress in Geography, 26(5): 11-22. (in Chinese)

Grasso M, Moneo M, Arena M, 2014. Assessing social vulnerability to climate change in Samoa. Regional Environmental Change, 14: 1329-1341.

Holling C S, 2001. Understanding the complexity of economic, ecological, and social systems. Ecosystems, 4(5): 390-405.

Huang Li, Shen Lianfeng, Wu Mingzuo, 2006.Analysis and assessment of the eco-environment frangibility of Henan Province. Henan Science, 24(4): 596-599. (in Chinese)

IMF, 2007. World Economic Outlook Database [DB/OL]. http://www.imf.org/external/pubs/ft/weo/2007/02/index.htm.

Janssen M A, 2007. An update on the scholarly networks on resilience, vulnerability, and adaptation within the human dimensions of global environmental change. Ecology and Society, 12(2): 9.

Janssena M A, Schoon M L, Ke W et al., 2006. Scholarly networks on resilience, vulnerability and adaptation within the human dimensions of global environmental change. Global Environmental Change, 16(3): 240-252.

Rosenthal J K, Kinney P L, Metzger K B, 2014. Intra-urban vulnerability to heat-related mortality in New York City, $1997-2006$. Health \& Place, 30: 45-60.

Kelly P M, Adger W N, 2000. Theory and practice in assessing vulnerability to climate change and facilitating adaptation. Climatic Change, 47(4): 325-352.

Koh J, 2011. Local Vulnerability assessment of climate change and its implications: The case of Gyeonggi-Do, Korea. Local Sustainability, 1: 411-427.

Li He, Zhang Pingyu, 2011. Research progress and prospective applications of vulnerability approach under global change. Progress in Geography, 30(7): 920-929. (in Chinese)

Liu Yi, Huang Jianyi, Ma Li, 2010. The assessment of regional vulnerability to natural disasters in China based on DEA model. Geographical Research, 29(7): 1153-1162. (in Chinese)

Liu Yanhua, Li Xiubin, 2010. Fragile Ecological Environment and Sustainable Development. Beijing: The Commercial Press. (in Chinese)

Liverman D M, 1990. Vulnerability to global environmental change. In: Kasperson, R E, Dow, D G, Kasperson J X (eds.), Understanding Global Environmental Change: The Contributions of Risk Analysis and Management. Worchester: Clark University.

Liverman D M, 2008. Assessing impacts, adaptation and vulnerability: Reflections on the Working Group Ii Report of the Intergovernmental Panel on Climate Change. Global Environmental Change, 18: 4-7.

McCarthy J J, Canziani O F, Leary N A et al., 2001. Climate Change 2001: Impacts, Adaptation, Vulnerability. Cambridge: 
Cambridge University Press.

Muller A, Reiter J, Weiland U, 2011. Assessment of urban vulnerability towards floods using an indicator-based approach: A case study for Santiago de Chile. Natural Hazards \& Earth System Sciences \& Discussions, 11(8): 2107-2123.

Newell B, Crumley C L, Hassan N, 2005. A conceptual template for integrative human-environment research. Global Environmental Change, 15: 299-307.

Nhuan M T, Hien L T T, Ha N T H et al., 2014. An integrated and quantitative vulnerability assessment for proactive hazard response and sustainability: A case study on the Chan May-Lang Co Gulf area, Central Vietnam. Sustainability Science, 9: 399-409.

Oluoko-Odingo AA, 2011. Vulnerability and adaptation to food insecurity and poverty in Kenya. Annals of the Association of American Geographers, 101(1): 1-20.

Piegorsch W W, Cutter S L, Hardisty F, 2007. Benchmark analysis for quantifying urban vulnerability to terrorist incidents. Risk Analysis, 27(6): 1411-1425.

Renaud F, Perez R, 2010. Climate change vulnerability and adaptation assessments. Sustainability Science, 5: 155-157.

Roberts M G, Yang Guoan, 2003.The international progress of sustainable development research: A comparison of vulnerability analysis and the sustainable livelihoods approach. Progress in Geography, 22(1): 12-21.

Seraj S M, Badruzzaman A B M, 1997.Potential hazards and vulnerability in urban development of Dhaka city, Bangladesh. Engineering Geology and the Environment, 1-3: 1487-1492.

Siagian T H, Purhadi P, Suhartono S, Ritonga H, 2014. Social vulnerability to natural hazards in Indonesia: Driving factors and policy implications. Natural Hazards, 70(2): 1603-1617.

Su Fei, Zhang Pingyu, Li He, 2008.Vulnerability assessment of coal-mining cities' economic systems in China. Geographical Research, 27(4): 907-916. (in Chinese)

Swift J, 1989. Why are rural people vulnerable to famine? IDS Bulletin, 20(2): 8-15.

Tian Yaping, Xiang Qingcheng, Wang Ping, 2013. Regional coupled human-natural systems vulnerability and its evaluation indexes. Geographical Research, 32(1): 55-63. (in Chinese)

Urban Social and Economic Survey Team of National Bureau, 2004. China Urban Development Report. Beijing: China Statistics Press. (in Chinese)

Usha T, Murthy M V R, Reddy N T, Mishra P, 2012. Tsunami vulnerability assessment in urban areas using numerical model and GIS. Natural Hazards, 60(1): 135-147.

Wang Yan, Fang Chuanglin, 2013. Urban vulnerability: Progress and prospect. Progress in Geography, 32(5): 755-768. (in Chinese)

Watson R T, Zinyowera M C, Moss R H, 1996. Climate Change 1995: Impacts, Adaptations, and Mitigation of Climate Change. Cambridge: Cambridge University Press.

White G F, Haas J E, 1975. Assessment of Research on Natural Hazards. Cambridge: MIT Press.

Yang Haijun, Xiao Lingji, Zou Zeqing, 2008. On judgment standard of industrialization stage, the flaw and revision of Hoffman coefficiency: Evidence from Jiangxi \& Jiangsu. Collected Essays on Finance and Economics, (2): 7-14. (in Chinese)

Ye Yuming, 2001. Approach on China's urbanization quality. China Soft Science, (7): 27-31. (in Chinese)

Yi Lixin, Zhang Xi, Ge Lingling et al., 2014. Analysis of social vulnerability to hazards in China. Environmental Earth Sciences, 71: 3109-3117.

Zhang Weixi, 2006. A study and assessment on vulnerability of the regional development [D]. Tianjin: Tianjin University. (in Chinese)

Zhao Guojie, Zhang Weixi, 2006. A study on vulnerability of the region economy and society-Hebei. Shanghai Economy Research, (1): 65-69, 96. (in Chinese)

Zhou Yang, Li Ning, Wu Wenxiang et al., 2014. Assessment of provincial social vulnerability to natural disasters in China. Natural Hazards, 71(3): 2165-2186. (in Chinese) 